\title{
Children's services in the new NHS-a struggle for survival?
}

\author{
W J Appleyard
}

At the present time of change, muddle, and uncertainty in the health service, there are opportunities to improve services for children if we can build on the certainty of our commitment to an integrated child health service. In reply to the British Paediatric Association's (BPA) response to the government's white paper Working for Patients, the Secretary of State, Mr Kenneth Clarke, wrote 'I am aware that successive expert studies-the Court report, the Maternity Services Advisory Committee reports-have described the need for integration [of comprehensive hospital and community services for children] and I have no doubt that this is necessary for the effective delivery of services. I expect districts to share this view and to seek to contract for integrated children's services'. (K Clarke, letter to Professor June Lloyd, President of the BPA, 1989.)

Under the new arrangements each district health authority or any number of health authorities joining together to form a consortium 'purchaser' will be reviewing the medical services in their districts. As child health surveillance is now primarily to be undertaken in general practice, it is essential that a comprehensive consultant children's service is organised to support the acute needs of children and those discovered during the surveillance programmes in each health district.

(1) A comprehensive child health service The overall picture has evolved from three important source documents. Firstly, the Faculty of Community Medicines 'An integrated child health service-a way forward', the BMA Council's child health forum, ${ }^{2}$ and the BPA's published 'response' to the government's white paper. ${ }^{3}$

An integrated child health service includes two complementary aspects: firstly, the indentification of the needs of all children within a geographical area and secondly, that individual children achieve and maintain optimum health and development. Thus a service should cover:

(a) General responsibilities to all children, whether resident, cared for, or in school within the district health authority boundaries.

(b) Specific responsibilities for children with 'special' or particular needs (including those at risk from child abuse) regarding their health, development, emotional and social condition, and support to their families incorporating child psychiatry, a child development unit, with services for mentally handicapped children.

(c) Statutory, collaborative, and cooperative arrangements with local authorities-for example, to comply with the 1981 Education Act and 1989 Children's Act.

(d) The school health service.

(e) A comprehensive children's department in a district general hospital incorporating (i) inpatient facilities, (ii) day care, (iii) outpatients, (iv) accident and emergency departments with children's facilities, and (v) maternity and neonatal services, all departments providing short term intensive care and some units longer term neonatal intensive care.

(f) Monitoring and evaluation of the effectiveness of the total service including the child health surveillance programme.

(g) Active health promotion and accident prevention programme.

(h) Access to tertiary care-that is, the paediatric specialties both regional and supraregional. ${ }^{4}$

\section{(2) Resource management}

With the new management structure the government is extending and accelerating the existing resource management initiative (RMI). There are two elements to RMI-the organisation of the 'operational unit' and the information required to sustain and develop it. Essentially all the resources of the unit, medical, nursing, clerical and therapeutic staff, together with the drug budget, etc, are brought together and managed by the medical director supported by a senior nurse and medical secretary (with at least the general administrative grade).

The integrated child health service could be built up of several interdependent 'resource' units. For example, acute inpatient and outpatient and day care services, the neonatal services including where appropriate intensive care, child development units, and school health, child psychiatry, etc.

These would in turn come within a paediatric 'clinical directorate'. Thus each consultant led resource unit would be operationally responsible and improved collaborative services could be developed through the clinical directorate. 
(3) The new 'contracts'

The general guidance issued by the Chief Executive, Mr Duncan Nichol, envisages 'the viability of any unit, and its ability to grow both in size and in quality, will depend on its ability to secure contracts. This in turn depends on harnessing the skills of its staff and securing their commitment to the contracts'. Unit managers 'should therefore seek the views of, and secure the broad support of, their staff to their contract plans. The active involvement of clinicians and others will be required in drawing up the service and quality specification elements of contracts'. Regional and supraregional paediatric specialist services will probably be contracted on a cost per case basis either by the district health authority (the purchaser) or by the 'provider' who will have to forecast the likely cost of this service in its contract with the purchaser.

We will therefore need to insist, in line with the Secretary of State's intent, that contracts are drawn up for an integrated child health service and that the 'specifications' in them of quality are in line with professional guidelines particularly with regard to paediatric staffing. For example, the 'safety net' is essential for the provision of an acute inpatient paediatric service with neonatal intensive care, and the numbers and grades of nursing staff on children's wards should be at least at the 'safe' level advised by the Royal College of Nursing. ${ }^{7}$ It would be acting as a hostage to fortune if contracts were agreed without these safeguards.

Contracting parties are encouraged to incorporate arbitration clauses in their contracts. Where disputes arise on professional matters, regional specialist advice will need to be sought. The recognised professional bodies such as the Medical Royal Colleges should act as the 'find' arbiters through the mechanism of the Joint Consultants Committee. Any contract would be publicly available once they have been signed.

Where either party believes the other is making use of an unfair advantage over the other to improve contract terms, the Secretary of State will have powers under the bill to resolve disputes. First the regional health authority in which either the purchaser or provider is situated, or both regional health authorities jointly, should attempt to conciliate between both parties. If this is not possible, the Secretary of State will have the power to determine the dispute himself or appoint others to do so. For instance if the purchaser refused to contract for a 'safe' level of service, an appeal should be made-which could go on to the Secretary of State. Then if he should impose the contract it would become public knowledge that an unsafe level of service had been imposed. Clinicians should not willingly 'contract' for an unsafe service. At present they may be forced to do so by default.

\section{(4) Two problem areas}

There are two aspects of the 'Working for Patients' initiative that could seriously undermine our aim to provide a comprehensive consultant children's service-the specimen contract documentation recently published and the present concept of self governing hospitals (NHS Trusts).

The 'specimen contract documentation' promoted by the Chief Executive of the NHS Management Executive ${ }^{8}$ includes as an example the West Suffolk Health Authority's contract for community services. Incorporated within this are the community paediatric . services undertaking the surveillance of the development of all children in West Suffolk (approximately 48000 ), identification and management of those with a handicap, and the assessment of those with special educational needs. This is apparently to be a separately managed unit not led clinically by consultants associated with the acute hospital units. The continuation and strengthening of the separate management structure, clinically distinct and distant from the general consultant children's services, will destroy our carefully prepared moves towards an integrated service.

An NHS Trust could but would not need to incorporate an integrated service. Indeed the current proposals in the Lewisham and North Southwark district are to establish Guy's Hospital as part of an NHS Trust, which would include Guy's paediatric unit. It would be separate from the community services NHS Trust (V A Shrubb, personal communication) where the senior clinical medical officers are to be responsible to managers rather than consultants. This is a terrible foretaste of how such a division could be organised elsewhere.

It is understood that there is evidence from the four health district studies undertaken in collaboration with the BPA that the consultant led service is more effective and efficient than a service that is not led by a consultant. The creation of separately managed 'community' units will be an unnecessarily expensive duplicate service just when we have the opportunity of utilising children's service budgets more wisely.

The second serious threat to an integrated service also relates to the self governing hospital or what is more recently being called the NHS Trust. There are some attractions to the concept of a 'trust' including the ability to raise its own capital, but there are at present overwhelming arguments against it. Any capital realisation will in any event be subject to central control by the public sector borrowing limit. More serious than that, consultant contracts will be transferred to the NHS Trusts. The current national terms and conditions of service will apply on day one. On day two the local manager can seek to change them and consultants will then be subject to local bargaining.

The 'provider' manager may wish to dispense with some or all of a consultant's services, introduce a short term contract, or insist that consultants are compulsorily resident. He may introduce performance related pay and he almost certainly will not wish consultants to express an independent opinion which could call into question the performance of his provider unit. In other words the current paragraph 330 of the terms and conditions of service 
which gives consultants this freedom of expression will be removed. The national pay structure for specialists was part of the original concept of a 'National' Health Service so that high quality specialist care can be available for all, not just patients with access to 'centres of excellence'. This policy has led to a much more evenly spread quality consultant service. Local pay bargaining would bring back a two tier system.

Unless proper safeguards are introduced the current advice to consultants must remain don't sell your birthright for 30 pieces of silver. In an NHS Trust consultants are likely to find themselves trapped in a system surrounded by broken promises.

\section{(5) Medical advice}

We have become accustomed to giving medical advice via the district medical advisory committee on the provision of children's services. As the 'purchaser' function is to be separated from the 'provider', consultants working in provider units will not be allowed to give advice to the purchasers of their services. Such medical advice will have to come from without the health district. It is vital therefore that paediatric consultants provide this advice at regional level through the paediatric specialist subcommittees. Paediatric specialist subcommittees should be strengthened with an 'audit' function to ensure that the clinical standards advised by the Royal College of Physicians and the BPA are being implemented.

The mechanism whereby purchaser units can obtain medical advice has not yet been clarified. They will of course have the services of the director of public health medicine. Each director of public health medicine will be expected to provide an annual report. We should seek to include a regular section on the children's services in this report, which could be brought to the attention of the district health authority and the local community.

\section{(6) Survival checklist}

In summary a suggested survival checklist is:

(1) Insist on your local children's services being organised in a fully integrated way along the lines agreed by the Secretary of State.

(2) Build up your services with resource managed units each with a paediatric clinical director, senior nurse, and a medical secretary of the general administrative grade and combine these resource units to form a clinical directorate.

(3) Insist on proper supportive information provided by relevant information technology.

(4) Make sure the RMI is fully developed before considering becoming an NHS Trust. Only in this way can local management demonstrate that they have the necessary management skills.

(If the RMI works well there may be no clinical advantage of a Trust and many potential disadvantages).

(5) Insist on the continuation of paediatric advice to regional health authorities.

(6) Insist on the evolution and growth of the regional and supraregional paediatric specialties.

1 An integrated child health service-a way forward. London: Faculty of Community Medicine, Dec 1987.

2 Appendix VIII: Interim report of the child health forum (BMA Annual Report of Council.) Br Med $\mathcal{J}$ 1986;292: 1409.

3 Response of the British Paediatric Association to the white paper 'Working for patients'. London: BPA, June 1989.

4 Appleyard WJ, Jackson ADM. Paediatric manpower: towards the 21 st century. Arch Dis Child 1988;63:1094-8.

5 Appleyard WJ. The National Health Service White Paper. Will it work for patients? Arch Dis Child 1989;64:643-5.

6 Hospital medical staffing: achieving a balance. Plan for action. 1987:30(para 58)

7 Royal College of Nursing. Paediatric Nurse Manager's Forum-Society A. Paediatric Nursing Newsletter. Autumn 1989.

8 Nichol DK. Contracts for health services-operating contracts. London: HMSO, 1990. (Department of Health EL(90) $\mathrm{MB} / 24,27.2 .90$.) 